\author{
Brian L. Griffin \\ University of Toronto, Toronto, Ontario, Canada
}

\title{
Scientific progress or organizational innovation? A comparison of two turns in Library and Information Science (Paper)
}

\begin{abstract}
:
This paper discusses the transformation of library and information science (LIS) from a discipline narrowly concerned with classification and preservation in libraries and archives to one that includes a wide range of fields and professional training programs. Two alternative but not mutually exclusive explanations may account for these developments. These changes could reflect normal scientific progress as the discipline matures. The changes could also be the result of isomorphic organizational changes in response to shifts in the environment and a need to realign the institutional logics of educational and professional organizations with those of the academy. These explanations are explored through a comparison of two periods during which LIS experienced rapid disciplinary and organizational changes: the decades during and after World War II and the final decade of the $20^{\text {th }}$ century. These abbreviated case studies suggest that both explanations of disciplinary change provide some analytical leverage for explaining different aspects of the development of LIS.
\end{abstract}

\section{Introduction}

The discipline of library and information science (LIS) was initially concerned with practical issues, such as classification and preservation, the training of professional librarians and archivists, and providing the public service of storing and retrieving cultural artifacts. ${ }^{1}$ In the decades after World War II, library schools shifted their focus from library science to information science or library and information science (Shera 1983; Olson and Grudin 2009, 156). During the past decade, a growing number of library schools have joined the iSchool movement and adopted its mandate to promote "expertise in all forms of information [that is] required for progress in science, business, education, and culture." (iSchools 2017b; see also Olson and Grudin 2009). This paper explains these shifts in LIS. Although histories of libraries and librarianship abound, most are descriptive and lack any critical or theoretical framework to explain the changes that have shaped the LIS discipline (for examples, see R. M. Harris 1992; M. H. Harris, Hannah, and Harris 1998). Unlike the existing histories of the discipline, this paper uses sociological theories of both scientific progress and institutional isomorphism to explain this history by comparing the cases of disciplinary change: in the decade during and after WWII and in the early $21^{\text {st }}$ century.

\footnotetext{
${ }^{1}$ Whether LIS constitutes a discipline in the traditional sense of the word remains an open question (on the definition of discipline, see Fuller 1991). For the purposes of this discussion, LIS is assumed to be a coherent practice of students and faculty situated in North American iSchools and library schools accredited by the American Library Association (ALA).
} 


\section{Explaining the development of a discipline}

Sociology of science and organizational theory provide two alternative but perhaps complementary explanations of disciplinary change. First, central to many studies of the history and sociology of science is the work of Kuhn (1996), who sought to explain how scientific disciplines developed and progressed. In Kuhn's explanation of scientific progress, the concept of paradigm is central. Paradigm represents "the entire constellation of beliefs, values, techniques, and so on shared by the members of a given community" (Kuhn 1996, 175) as well as the "concrete puzzle-solutions which, employed as models or examples, can replace explicit rules as a basis for the solution of the remaining puzzles of normal science" (Kuhn 1996, 175). These two meanings of paradigm are important for the development of LIS because it is a multiple paradigm science (on multiple paradigm social science, see Ritzer 1975), and in multiple paradigm sciences, paradigm shifts are lateral shifts to a new ontological or epistemological perspective. The paper illustrates the concepts of paradigm and progress with examples from LIS.

Second, institutional isomorphism provides an alternative theoretical explanation of organizational and disciplinary change. In this approach, organizations refer to collections of individuals that "produce similar services or products" each with a particular "institutional life" that shapes organizations and their relationships, often resulting in homogenization (DiMaggio and Powell 1983, 148). This homogenization is due to several kinds of isomorphic mechanisms including coercive, mimetic and normative isomorphisms that extend pressures from the state and professionals within the field. The paper explains examples of these three types of isomorphic pressures in LIS to highlight the usefulness of this alternative theoretical explanation of disciplinary change.

\section{Two comparative historical case studies}

The discipline of librarianship experienced rapid changes in its substantive and methodological focus during the periods of the two historical case studies. The disciplinary changes were reflected in the rebranding of the discipline's educational programs, organizations, and scholarly publications. Both case studies are illustrated with historical examples and evidence from primary and secondary documents.

First, during and after World War II, changes in the discipline reflect normal scientific progress within a paradigm, as imagined by Kuhn. However, the changes were also responses to external norms, pressures, or demands emanating from the environment, as explained by organizational theory. This case also suggests that new technologies can prompt changes in disciplines as both a normal outcome of scientific pursuits and a contest to claim new disciplinary territory or status.

Second, by the end of the twentieth century, information scientists were preoccupied with the relationships between "information, people and technology" (iSchools 2017a). The recent turn toward a focus on information technologies and culture can in part be explained as a natural extension of traditional concerns in LIS as it continues to develop as an academic discipline. However, many of the organization changes - the rise and fall of LIS schools and related organizations - are best understood through the lens of organizational and institutional theories, rather than a reflection of scientific progress. 


\section{Conclusions and future work}

This paper explains the trajectory of LIS by highlighting the primary factors that prompted two dramatic shifts in the discipline, first after WWII and again at the end of the $20^{\text {th }}$ century. In both periods, changes in technology expanded both the focus of the discipline (e.g., the shift from books to digital text) and the theories, methods, and tools used (e.g., social science theories and methods or the use of computers). While all social science disciplines are vulnerable to these kinds of pressures to some extent, LIS provides an interesting example because it must align with the interests of academics who pursue pure scholarship, the needs of students who require professional training, and the requirements of a variety of organizations that provide specific guidelines for membership. As a result, the development of LIS has followed a trajectory in both of these historical turns that reflects the Kuhnian approach to disciplinary change while also responding to external organizational and institutional constraints. 


\section{References}

DiMaggio, Paul J., and Walter W. Powell. 1983. 'The Iron Cage Revisited: Institutional Isomorphism and Collective Rationality in Organizational Fields'. American Sociological Review, 147-60.

Fuller, Steve. 1991. 'Disciplinary Boundaries and the Rhetoric of the Social Sciences'. Poetics Today 12 (2): 301.

Hall, Richard H. 1968. 'Professionalization and Bureaucratization'. American Sociological Review, 92-104.

Harris, Michael H., Stan A. Hannah, and Pamela C. Harris. 1998. Into the Future: The Foundations of Library and Information Services in the Post-Industrial Era. Greenwood Publishing Group.

Harris, Roma M. 1992. Librarianship: The Erosion of a Woman's Profession. Ablex Publishing Corporation.

iSchools. 2017a. 'Charter'. iSchools. http://ischools.org/about/charter/.

_. 2017b. 'Motivation'. iSchools. http://ischools.org/about/history/motivation/.

Kuhn, Thomas S. 1996. The Structure of Scientific Revolutions. 3rd. ed. Chicago: University of Chicago Press.

Olson, Gary M., and Jonathan Grudin. 2009. 'The Information School Phenomenon'. Interactions 16 (2): 15-19. doi:10.1145/1487632.1487636.

Ritzer, George. 1975. 'Sociology: A Multiple Paradigm Science'. The American Sociologist 10 (3): $156-67$.

Shera, Jesse H. 1983. 'Librarianship and Information Science'. In The Study of Information: Interdisciplinary Messages, edited by Machlup, Fritz and Mansfield, Una, 379-88. New York: Wiley and Sons. 